\title{
Short Communication: Investigation of leaf architectural patterns: Implications in delineating taxonomically controversial Hoya merrillii Schlechter and Hoya quinquenervia Warburg
}

\author{
DIANA P. PAGUNTALAN ${ }^{1, \boldsymbol{v}}$, INOCENCIO E. BUOT JR.,3, \\ ${ }^{1}$ Division of Biological Sciences, College of Arts and Sciences, University of the Philippines-Visayas. Miagao, Iloilo, Philippines. \\ Tel.: +63-33-315-9494, ’email: dppaguntalan@up.edu.ph \\ ${ }^{2}$ Institute of Biological Sciences, College of Arts and Sciences, University of the Philippines Los Baños. College, Laguna, Philippines."vemail: iebuot@up.edu.ph \\ ${ }^{3}$ Faculty of Management and Development Studies, University of the Philippines Open University. Los Baños, Laguna
}

Manuscript received: 12 December 2018. Revision accepted: 25 February 2019.

\begin{abstract}
Paguntalan DP, Buot JrIE. 2019. Short Communication: Investigation of leaf architectural patterns: Implications in delineating taxonomically controversial Hoya merrillii Schlechter and Hoya quinquenervia Warburg. Biodiversitas 20: 833-839. Variations in leaf traits of two very likely similar plants, Hoya merrillii Schlechter and Hoya quinquenervia Warburg were examined together with an outgroup, Hoya cagayanensis Burton. The objectives of the study are to examine the leaf architectural characteristics of Hoya merrillii and Hoya quinquenervia and use the information as an additional basis of delineation between the said species of Hoya plants. Thirty leaf samples for each species were examined for laminal and vein characters. The characters laminar size, laminar shape, number of basal veins, quinternary vein fabric, areole development and characteristics of FEVs (free-ending veins), were well-defined from either one or both species. Overall, the results showed variability between the studied plant groups using univariate and multivariate analysis. The data ordination on the morphometric traits using PCOa showed distinct groupings among studied leaf samples and yielded consistent results with the single linkage or nearest neighbor cluster dendrogram which showed distinct clustering of individual species in terms of morphometric traits that were considered in the study. Detected variations of the leaf architectural traits on the leaves of Hoya merrillii Schlechter and Hoya quinquenervia Warburg allowed for the more available basis of separation in addition to established floral morphologies that are primarily used as criteria for delineation between species. Variations in leaf architecture characters can be of great value to illustrate or imply meanings in the taxonomic relationships of the Hoya species studied.
\end{abstract}

Keywords: Hoya cagayanensis, Hoya merrillii, Hoya quinquenervia, leaf architecture

\section{INTRODUCTION}

The architectural properties of leaf venation are recent of interest because of its importance in classifying plants (Zetter 1984; Kohler 1993). This is especially true in the case of angiosperm leaves because they show diverse variation and intricate branching patterns in their veins. This is manifested in one important feature of anastomosing veins which fairly distinguish many angiosperm leaves. Hickey (1993) put emphasis on the immeasurable value of leaf architectural patterns in establishing evolutionary and ecological relationships among plants. The possible interrelationships between the venation systems and the function they serve in the entire leaf and how these different venation patterns came about as a function of evolution are also being explored (RothNebelsick et al. 2001). With the above-mentioned usefulness of investigating leaf architectural patterns, several plant species of conflicting or vague nomenclatural labels can be reinforced with supplemental information that will add to our understanding of their proper identity.

Hoya is one genus in the plant family Apocynaceae that is comprised of a large number of published species of about 350-450 species (Rodda 2015) making it taxonomically complex. Majority of Hoya species are found hanging on branches of trees as epiphytes (Kloppenburg 2006) and are commonly known as wax plants. Of the several Hoya species, Hoya merrillii, and Hoya quinquenervia have oftentimes created confusion among herbalists as they are practically almost similar in floral and leaf appearance and the dilemma regarding their distinction have been a pressing issue (Valenzuela, pers. comm.). In Kloppenburg's monograph of Philippine Hoya species (1991), both $H$. merrillii and $H$. quinquenervia were individually described. Both species are palmately netted except that H.merrillii can have 3-5 nerves. Leaves also of both are ovate in shape but noted to be quite more broadly for $H$. quinquenervia. The inflorescence of both come in umbels and flowers of yellow corolla lobes, noting only the subtle purplish markings for $H$. quinquenervia. Despite the established phenotypic plasticity of leaf characters, the author finds it useful still to look at leaf characters as they have been found to have geneticallyfixed and stable venation patterns (Roth-Nebelsick et al. 2001) and also since this field's taxonomic potential remains poorly explored (Banaticla and Buot 2004; Jumawan and Buot 2014; Salvana and Buot 2016; Torrefiel and Buot 2017). Leaf architectural studies are also used to 
examine and characterize plant species within a family or to classify a specific plant taxa (Larano and Buot 2010), examine plant species in the genus level such as in Psychotria (Banaticla and Buot 2004), study plants that have no reproductive parts as in the case of sterile plants and fossils (Dilcher 1974; Hickey and Taylor 1991) and taxonomic investigation of leaf architecture in the delineation of several Hoya species in the Philippines like Hoya coriacea, Hoya halconensis, Hoya buotii (Salvana and Buot 2014), Hoya incrassata and Hoya crassicaulis (Villareal and Buot 2015).

This study is purposed to describe the leaf morphological characteristics of Hoya merrillii and Hoya quinquenervia and aims to provide supplementary information on the current distinction between the two species.

\section{MATERIALS AND METHODS}

\section{Gathering and processing of leaf samples}

Thirty (30) mature leaf samples for each of Hoya merrillii and Hoya quinquenervia were collected. H.merillii leaves were acquired from Hoya plants being sold in Calamba, Laguna in the garden of Anne Valenzuela, an expert in Hoya identification, who herself verified the species, whereas leaves of $H$. quinquenervia were gathered from the Philippine Nuclear Research Institute, Diliman, Quezon City, Metro Manila under the supervision of a research specialist, Mr. Jorge Sahagun. Taking the credibility of the source of the plant materials, the authors did not find the need to secure a verification certificate. The leaf samples were all orderly spaced and placed in a tabloid size clean newspaper, placed in a plant press and sun-dried until leaves are totally dry. The leaves were then pressed against two 8 in. X 6 in. glass sheets and hanging over the top of a hollow container with a light source inside, creating a sort of a light box. The light passing through the thin dehydrated leaves allowed for clear and distinct visualization of the veins. It is observed that for succulent leaves, drying and examining through a light box is the most convenient way as one may opt not to do leaf clearing since once the leaves are well-dehydrated, the leaf becomes too thin and are ideal for direct examination under a light source directly placed beneath the leaves.

\section{Investigation of leaf architectural characters}

The leaf architecture for each plant of the study was described using characters and terminologies of Hickey (1973), Leaf Architecture Working Group (1999), and that of Ellis et al. (2009). Measurements such as leaf width and length were done using a transparent ruler while angles of divergence were measured using a protractor. A dichotomous key was constructed using characters on leaf architectural details described in this study.

\section{Data analysis}

A number of characters were selected and each of its character states was assigned as values. PAST (Paleontological Statistical Software ver.3.19) software was used to analyze the data generated using multivariate and univariate analyses. The minimum value, maximum value, mean and standard deviation where determined for univariate data and sets were plotted in a box chart to evaluate the distribution of data. The Morisita index of similarity was used for the multivariate data matrix. The similarity matrix was explored using data ordination technique. Ordination refers to the projection of multivariate data sets in a two-dimensional space to detect patterns upon visual inspection (Pielou 1984). Principal coordinate analysis (PCOa) or also known as metric multidimensional scaling was implemented as data ordination (Gower 1966). PCOa reduces the dimensionality of the data similar to principal component analysis but the advantage of PCOa is that it may be used with all types of variables (Legendre and Legendre 1998). Cluster analysis was performed combining quantitative data into clusters in constructing a dendrogram. The resulting pattern generated from multivariate analysis detected variations in leaf morphometric traits.

\section{Descriptions of the three studied species based on leaf characterization from this study}

Hoya merrillii Schlechter. Blade elliptic, notophyll to mesophyll, 32-57mm wide, 99-155mm long, apex acuminate, base convex, medially symmetrical, entire, unlobed. Venation acrodromous, 3 basal veins, quintuplinerved, $2^{\circ}$ festooned brachidodromous, spacing gradually increasing proximally, excurrent, angle smoothly increasing proximally, epemedial and intercostal $3^{\circ}$ irregularly reticulate, tertiary course looped, higher vein order distinct; $4^{\circ}$ irregularly reticulate; highest vein order $5^{\circ}$ freely ramifying, areolation good, veinlets branched (Figure 4A, D-E). Exsicc. - Paguntalan and Buot 6890 (PBDH)

Hoya quinquenervia Warburg. Blade broadly-elliptic, notophyll to mesophyll, 43-62mm wide, 69-120mm long, apex shortly-acuminate, base rounded, medially symmetrical, entire, unlobed. Venation acrodromous, 5 basal veins, palmate, $2^{\circ}$ simple to festooned brachidodromous, spacing gradually increasing proximally, excurrent, angle smoothly increasing proximally, epemedial and intercostal $3^{\circ}$ irregularly reticulate, tertiary course looped, higher vein order distinct; $4^{\circ}$ irregularly reticulate; highest vein order $5^{\circ}$ freely ramifying, areolation moderate, veinlets branched (Figure 4B, F-G). Exsicc. Paguntalan and Buot 6891 (PBDH)

Hoya cagayanensis Burton. Blade elliptic, notophyll to mesophyll, 23-35mm wide, 65-99 $\mathrm{mm}$ long, apex acuminate, base convex, medially symmetrical, entire, unlobed. Venation acrodromous, 3 basal veins, quintuplinerved, $2^{\circ}$ festooned brachidodromous, spacing irregular, decurrent, angle smoothly increasing proximally, epemedial alternate percurrent and intercostal $3^{\circ}$ mixed percurrent, tertiary course looped, higher vein order distinct; $4^{\circ}$ irregularly reticulate; highest vein order $5^{\circ}$ freely ramifying, areolation good, veinlets branched (Figure 4C, H-I). Exsicc. - Paguntalan and Buot 6892 (PBDH) 


\section{RESULTS AND DISCUSSION}

The actual leaves and flowers of Hoya merrillii and $H$. quinquenervia as shown in Figure 1 show very subtle differences. Specific character states for both laminal and nerve characters are listed in Tables 1 and 2 . where the character states that separate H.merrillii and H.quinquenervia are highlighted. Laminar shape, apex shape, base shape, base angle, major secondary vein framework, number of basal veins, areolation and FEVs separate the two Hoya species. On the other hand, uniting characters include notophyll-mesophyll laminar size, acrodromous primary vein network, major secondary spacing that is gradually increasing proximally, smoothly increasing major secondary angle and also up to the intercostal and epemedial tertiary vein fabric which both showed irregular reticulate patterns.
The degree of areolation also varied for both species with H.merrillii having a good areolation category while H.quinquenervia showed a moderate category. Freely ending veinlets (FEVs) were also varied for H.quinquenervia exhibiting both dendritic and dichotomous branching while H.merrillii generally showed dendritic branching of FEVs. Variabilities in character traits within species may have been an attribute of environmental conditions such as stress (Van Valen 1962). The univariate statistics of the morphometric traits of the plant groups indicate that leaf size, quinternary vein fabric, and areolation were the most variable among the measured leaf characters while the least variable traits were medial symmetry and margin type and the major secondary vein fabric (Figure 2).

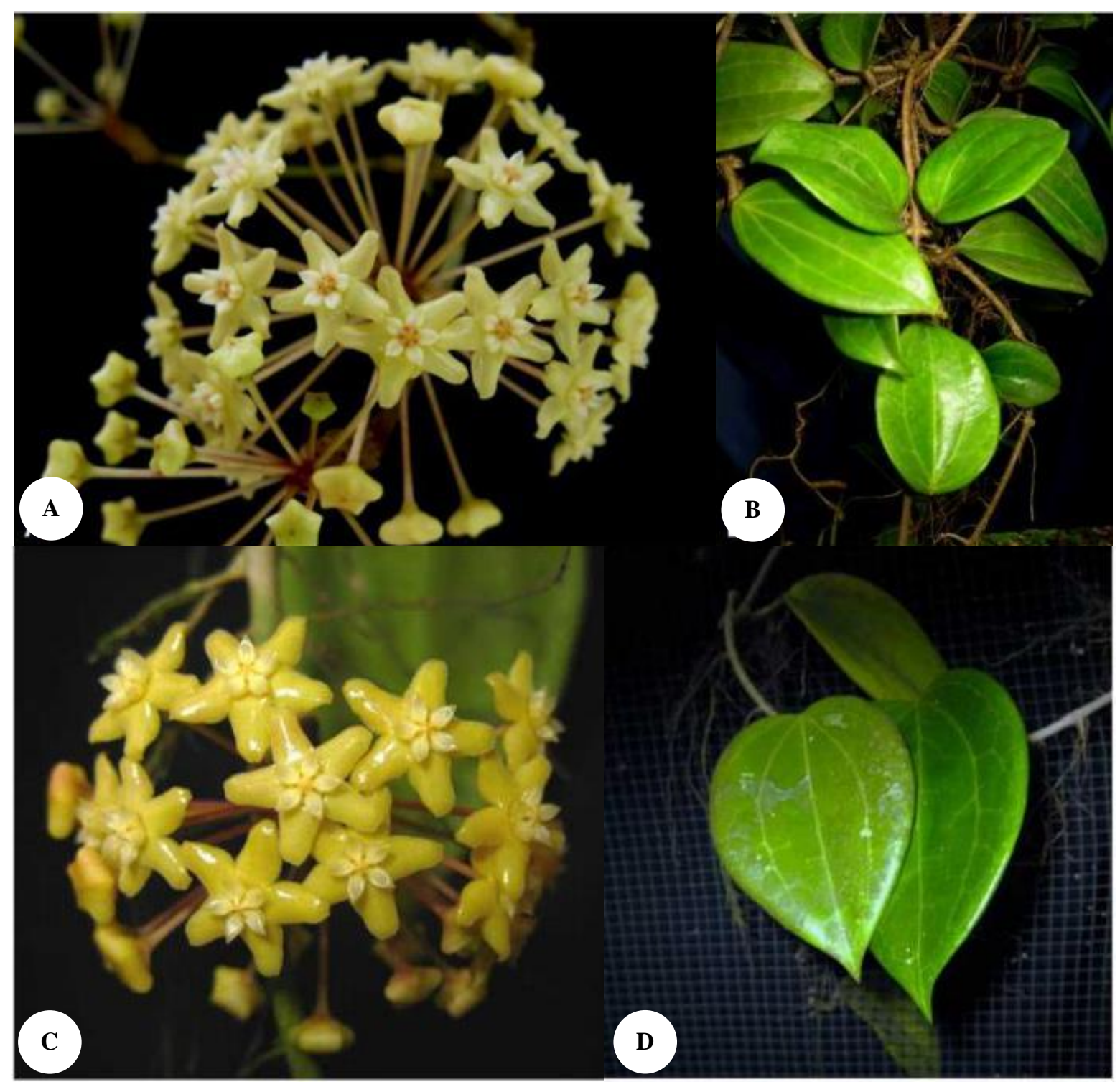

Figure 1. Inflorescences and leaves of Hoya merrillii (A-B) and Hoya quinquenervia (C-D). (Photographs: Jorge Sahagun, Philippine Nuclear Research Institute ) 
Table 1. General laminal characters of the three studied species, Hoya merrillii, Hoya quinquenervia, Hoya cagayanensis

\begin{tabular}{llll}
\hline Characters & Hoya merrillii & Hoya quinquenervia & Hoya cagayanensis \\
\hline Leaf attachment & petiolate & petiolate & petiolate \\
Leaf arrangement & opposite & opposite & spposite \\
Leaf organization & simple & simple & $23-35 \mathrm{~mm}$ \\
Laminar width & $32-57 \mathrm{~mm}$ & $63-62 \mathrm{~mm}$ & $65-99 \mathrm{~mm}$ \\
Laminar length & $99-155 \mathrm{~mm}$ & $2092.5-5040 \mathrm{~mm}$ & $1207.5-2388.75 \mathrm{~mm}$ \\
Laminar area & $2376-6540.75 \mathrm{~mm}$ & notophyll-mesophyll & microphyll-notophyll \\
Laminar size & notophyll-mesophyll & broadly-elliptic & elliptic \\
Laminar shape & elliptic & symmetrical & symmetrical \\
Medial symmetry & symmetrical & untoothed & untoothed \\
Margin type & untoothed & acute & acute \\
Apex angle & acute & shortly acuminate & acuminate \\
Apex shape & acuminate & acute-obtuse & acute \\
Base angle & acute & rounded & convex \\
Base shape & convex & & \\
\hline
\end{tabular}

Table 2. Leaf architectural characters of the three studied species, Hoya merrillii, Hoya quinquenervia, Hoya cagayanensis

\begin{tabular}{llll}
\hline Characters & Hoya merrillii & Hoya quinquenervia & Hoya cagayanensis \\
\hline Primary vein framework & acrodromous & acrodromous & pinnate \\
Number of basal veins & 3 & 5 & 1 \\
Major secondary vein framework & festooned brachidodromous & simple-festooned brachidodromous & festooned brachidodromous \\
Major secondary spacing & gradually increasing proximally & gradually increasing proximally & irregular \\
Major secondary angle & smoothly increasing proximally & smoothly increasing proximally & inconsistent \\
Major secondary attachment & excurrent & excurrent & decurrent \\
Intercostal tertiary vein fabric & irregular reticulate & irregular reticulate & alternate percurrent \\
Epimedial tertiaries & irregular reticulate & irregular reticulate & mixed percurrent \\
Exterior tertiary course & looped & looped & looped \\
Quaternary vein fabric & irregular reticulate & irregular reticulate & irregular reticulate \\
Quinternary vein fabric & freely ramifying & freely ramifying & freely ramifying \\
Areolation & good & moderate & good \\
FEVs & dendritic & dichotomous-dendritic & dichotomous \\
\hline
\end{tabular}

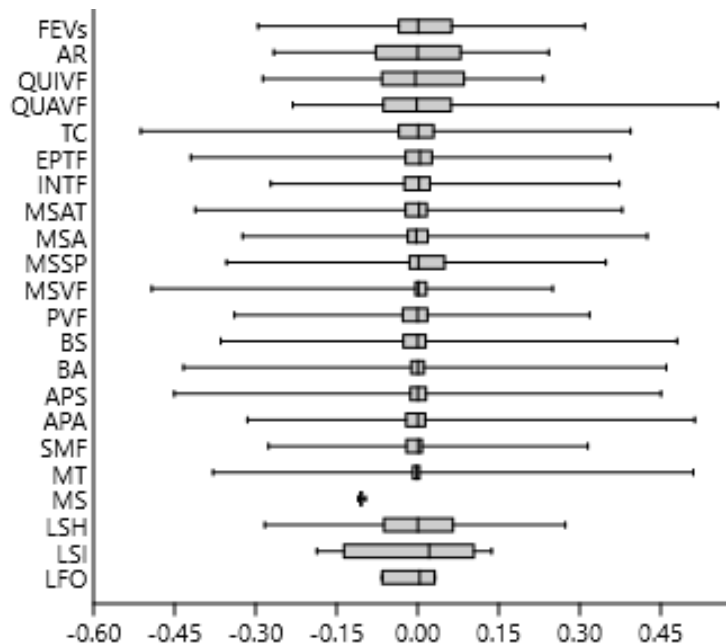

Figure 2. Boxchart on the univariate metrics leaf morphometric traits of the three studied plant species. Note: FEVs: Free Ending Veins, AR: Areolation, QUINVF: Quinternary Vein Fabric, QUAVF: Quaternary Vein Fabric, TC: Exterior Tertiary Course, EPTF: Epemedial Tertiary Fabric, INTF: Intercostal Tertiary Fabric, MSAT: MajorSecondary Attachment, MSA: Major Secondary Angle, MSSP: Major Secondary Spacing, MSVF: Major Secondary Vein Fabric, PVF: Primary Vein Framework, BS: Base Shape, BA Base Angle, APS: Apex Shape, APA: Apex Angle, SMF: Special Margin Feature, MT: Margin type, MS: Medial Symmetry, LSH: Leaf Shape, LSI: Leaf Size, LFO: Leaf Organization

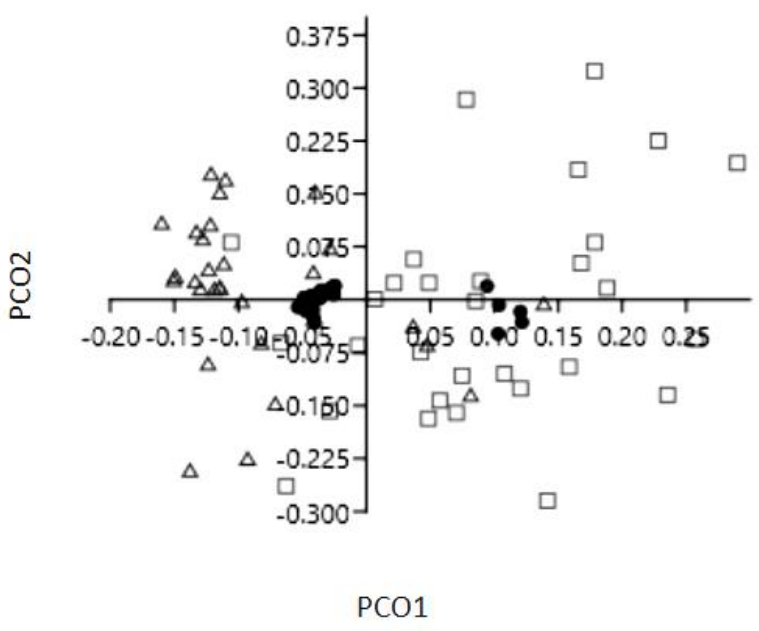

Figure 3. The data ordination on the morphometric traits contributed by the three plant species using PCOa

Variability and resemblances on the leaf morphometric traits between the plant species examined were shown in output patterns generated in data exploration using multivariate analysis. The data ordination of PCOa (Figure 3) shows the variation of the leaf morphometric traits among species studied and while there is overlapping closeness in some quadrant, the individual species still 
cluster distinctly indicating that leaf samples may appear similar in some traits but are generally distinct for most characters. This result emphasizes more on the significant variabilities between the two studied species indicating distinction between Hoya merrillii and Hoya quinquenervia.

Comparison of vascular patterns in Figure 4 shows that the basic separating characters for H.merrillii and $H$. quinquenervia is the number of veins, the former being quintuplinerved, with 3 basal veins and the latter being palmate having 5 basal veins. Both showed a festooned brachidodromous major secondary vein framework, but for H.quinquenervia, some leaf samples exhibited a simple brachidodromous secondary vein framework. Both species show irregular reticulate patterns in higher vein orders that is, the epemedial and intercostal tertiaries and in primary vein framework which is acrodromous.

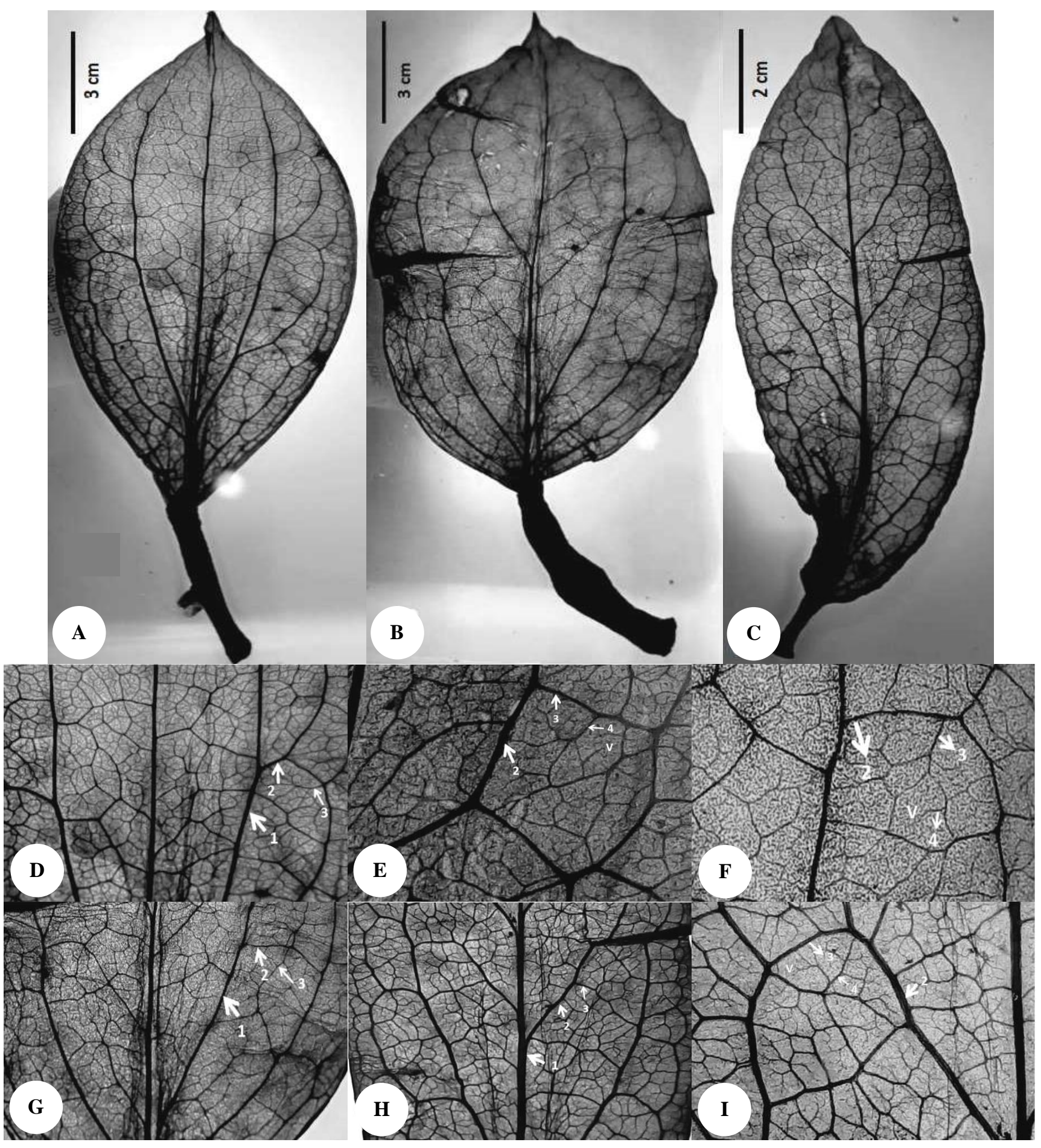

Figure 4. Venation patterns in examined leaves of Hoya merrillii (A, D-E), Hoya quinquenervia (B, F-G), and Hoya cagayanensis (C, $\mathrm{H}-\mathrm{I})$ showing vein orders and then the ultimate veinlet (v) 


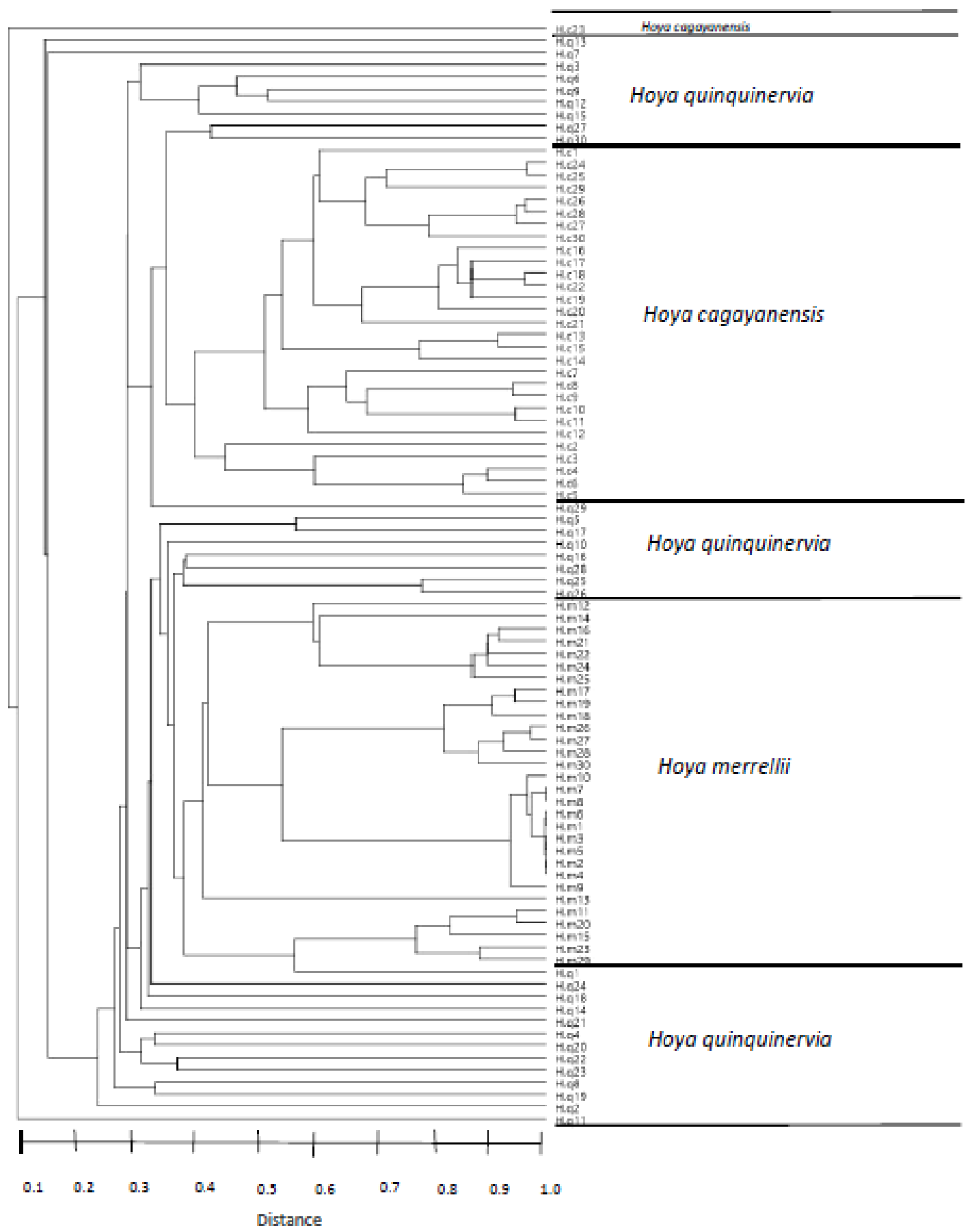

Figure 5. Single linkage or nearest neighbor cluster dendrogram on the twenty-four morphometric traits from the leaves of the studies plants

Clustering leaf samples depict the similarity of their most similar members. The dendrogram (Figure 5) visually displays the grouping together of most similar leaf samples such as in the case of H.merrillii wherein most leaf samples are in rows closest to each other. Several clusters connect H.merrillii close to H.quinquenervia at several rows but their distances are far indicating still the variability in the leaf morphometric traits for the individual leaf samples. Same is true for several clusters of close grouping between H.quinquenervia and $H$. cagayanensis, which is an outgroup.
In conclusion, several leaf characters such as size, symmetry, shape, and angle are common to Hoya species studied here. However, detailed characters of higher vein orders such as areolation and FEV characters which are considered good taxonomic markers showed more varied results, indicating distinctiveness among and between species studied. Generally, the analyses undertaken in the study yielded results that support the current distinct treatments between Hoya merrillii and Hoya quinquenervia. Detected variations of the morphometric traits on the leaves of both species allowed for a more 
available basis of separation in addition to established floral morphologies that are primarily used as criteria for delineation between species, hence confirming the hypothesis of Roth-Nebelsick et al. (2001) that leaf venation pattern is genetically fixed.

It is recommended that leaf architecture be used more in studies that aim to resolve conflicting plant identities and other taxonomic controversies since it is a useful tool in comparing physical manifestations, through venation patterns, of a fixed genetic makeup, and thus, are good taxonomic markers. Compared to molecular approaches that can be an option for researchers only if there are enough resources, leaf architectural analyses provides an inexpensive alternative.

\section{REFERENCES}

Banaticla MCN, Buot Jr IE. 2004. Leaf architecture of ten Philippine Psychotria species (Rubiaceae). Philipp Sci 41: 74-90.

Ellis B, Daly D, Hickey LJ, Johnson KR, Mitchell J, Wilf P, Scott W. 2009. Manual of Leaf Architecture. Smithsonian Institution, Washington, DC.

Gower JC.1966. Some distance properties of latent root and vector methods used in multivariate analysis. Biometrika 53: 325-338.

Hammer O, Harper DAT, Ryan PD. 2001. PAST: Paleontological Statistics Software package for education and data analysis. Paleontologia Electronica 4 (1): 9.

Hickey LJ, Taylor DW. 1991. The leaf architecture of Ticodendron and application of foliar characters in discerning its relationships. Ann Missouri Bot Gard 78: 105-130.

Hickey LJ. 1973. Classification of the Architecture of Dicotyledonous Leaves. Amer J Bot 60: 17-33.

Jumawan JH, Buor JrIE. 2017. Numerical taxonomic analysis in leaf architectural traits of some Hoya r. br. species (Apocynaceae) from Philippines. Bangladesh J Plant Taxon 23 (2): 199-207
Kloppenburg D. 2006. The World of Hoyas, A Pictorial Guide. Fresno, CA.

Kloppenburg RD. 1991. Hoya golamcoana Kloppenb. Fraterna 3rd Quarter, Philipp. Hoya sp. Suppl.: II, (as “golamcoiana")

Kloppenburg RD. 1991. Philippine Hoya Species: A Monograph. Orca Pub. Co., Medford, OR.

Koehler E. 1993. Blattnervatur-Muster der Buxaceae Dumortier und Simmondsiaceae Van Tieghem. Feddes Repertorium 104: 145-167.

Larano AAP, Buot IE. 2010. Leaf architecture of selected species of Malvaceae sensu APG and its taxonomic significance. Philippines J Syst Biol 14.

Leaf Architecture Working Group. 1999. Manual of Leaf Architecture Morphological Description and Categorization of Dicotyledonous and Net-Veined Monocotyledonous Angiosperms. Leaf Architecture Working Group, Washington, DC.

Legendre P, Legendre LFC. 1998. Numerical Ecology in Developments in Environmental Modelling. Vol. 24. Elsevier Science, New York.

Pielou EC. 1986. The interpretation of ecological data: a primer on classification and ordination. J Amer Stat Assoc 81 (395): 1-866.

Rodda M. 2015. Two new species of Hoya R.Br. (Apocynaceae, Asclepiadoideae) from Borneo. PhytoKeys 53: 83-93.

Roth-Nebelsick A, Uhl D, Moosbrugger V, Kerp H. 2001. Evolution and function of leaf venation architecture: A review. Ann Bot 87: 553566.

Salvana FRP, Buot JrIE. 2014. Leaf Architectural Study of Hoya coriacea, Hoya halconensis and Hoya buotii (Apocynaceae). Intl Res J Biol Sci 3 (3): 37-44.

Torrefiel JT, Buot JrIE. 2017. Hoya carandangiana, Hoya bicolensis, and Hoya camphorifolia (Apocynaceae) species delineation: Insights from leaf architecture. Thailand Nat Hist Mus J 11 (1): 35-44.

Van Valen L. 1962. A study of fluctuating asymmetry. Evolution 16: 125142.

Villareal AGM, Buot JrIE. 2015. Leaf Architecture of Hoya incrassata Warb.and Hoya crassicaulis Elmer x Kloppenb. (Apocynaceae): Taxonomic identification and Conservation Concerns. Intl $\mathrm{J}$ Ecol Conserv 15

Zetter R. 1984. Morphologische Untersuchungen an Fagus-Blae ttern aus dem Neogen von Oesterreich. Beitraege zur Palaeontologie von Oesterreich 11. Wien. 